\title{
BMJ Open Effectiveness and safety of herbal medicines for induction of labour: a systematic review and meta-analysis
}

\author{
Collins Zamawe, ${ }^{1}$ Carina King, ${ }^{1}$ Hannah Maria Jennings, ${ }^{1}$ Chrispin Mandiwa, ${ }^{2}$ \\ Edward Fottrell $^{1}$
}

To cite: Zamawe $\mathrm{C}$, King $\mathrm{C}$, Jennings $\mathrm{HM}$, et al. Effectiveness and safety of herbal medicines for induction of labour: a systematic review and meta-analysis. BMJ Open 2018;8:e022499. doi:10.1136/ bmjopen-2018-022499

- Prepublication history and additional material for this paper are available online. To view these files, please visit the journal online (http://dx.doi. org/10.1136/bmjopen-2018022499).

Received 22 February 2018

Revised 20 July 2018

Accepted 14 September 2018

Check for updates

(C) Author(s) (or their employer(s)) 2018. Re-use permitted under CC BY-NC. No commercial re-use. See rights and permissions. Published by BMJ.

${ }^{1}$ Faculty of Population Health Sciences, Institute for Global Health, University College London, London, UK ${ }^{2}$ School of Public Health, Tongji Medical College, Huazhong University of Science and Technology, Wuhan, China

Correspondence to

Collins Zamawe;

c.zamawe@ucl.ac.uk

\section{ABSTRACT}

Objective The use of herbal medicines for induction of labour (IOL) is common globally and yet its effects are not well understood. We assessed the efficacy and safety of herbal medicines for IOL.

Design Systematic review and meta-analysis of published literature.

Data sources We searched in MEDLINE, AMED and CINAHL in April 2017, updated in June 2018.

Eligibility criteria We considered experimental and nonexperimental studies that compared relevant pregnancy outcomes between users and non-user of herbal medicines for IOL.

Data extraction and synthesis Data were extracted by two reviewers using a standardised form. A randomeffects model was used to synthesise effects sizes and heterogeneity was explored through $\mathrm{I}^{2}$ statistic. The risk of bias was assessed using 'John Hopkins Nursing School Critical Appraisal Tool' and 'Cochrane Risk of Bias Tool'. Results A total of 1421 papers were identified through the searches, but only 10 were retained after eligibility and risk of bias assessments. The users of herbal medicine for IOL were significantly more likely to give birth within 24 hours than non-users (Risk Ratio (RR) 4.48; 95\% Cl 1.75 to 11.44). No significant difference in the incidence of caesarean section (RR 1.19; 95\% $\mathrm{Cl} 0.76$ to 1.86 ), assisted vaginal delivery (RR $0.73 ; 95 \% \mathrm{Cl} 0.47$ to 1.14 ), haemorrhage (RR $0.84 ; 95 \% \mathrm{Cl} 0.44$ to 1.60 ), meconiumstained liquor (RR $1.20 ; 95 \% \mathrm{Cl} 0.65$ to 2.23 ) and admission to nursery (RR $1.08 ; 95 \% \mathrm{Cl} 0.49$ to 2.38 ) was found between users and non-users of herbal medicines for IOL.

Conclusions The findings suggest that herbal medicines for IOL are effective, but there is inconclusive evidence of safety due to lack of good quality data. Thus, the use of herbal medicines for IOL should be avoided until safety issues are clarified. More studies are recommended to establish the safety of herbal medicines.

\section{INTRODUCTION}

Across the world, the use of unconventional or traditional medical therapies is very high. ${ }^{1-4}$ These non-biomedical remedies are together referred to as complementary and alternative medicines (CAMs). WHO recognises the role of CAM of verified quality, safety and efficacy in ensuring universal access to healthcare. ${ }^{5}$ As

\section{Strengths and limitations of this study}

Due to safety and ethical reasons, herbal medicines for pregnant women are rarely evaluated through randomised controlled/clinical trials (RCTs). Nonetheless, most of the reviews of herbal medicines during pregnancy are restricted to RCTs. The present review included non-experimental studies to assess a wider evidence base.

- No restrictions were applied on the date of publication, location, study design and types of treatment (herbal medicine used).

- There is lack of data on key outcomes (eg, maternal death and sepsis) and from low-income countries.

- Some analyses did not have sufficient statistical power due to the inadequate number of studies and small sample sizes.

such, for the period between 2014 and 2023, WHO traditional medicine strategy focuses on harnessing the potential contribution of CAM in healthcare and promoting its safe and effective use. ${ }^{5}$ Although this requires rigorous evidence on safety and efficacy of CAM, research in this area remains limited. ${ }^{5}$ Herbal medicine or medicinal plant is one of the well-known CAM therapies that involve the use of plants or plant extracts for therapeutic motives. ${ }^{6}$ As in the general population, the use of herbal medicines is common among pregnant women globally. ${ }^{7-10}$ The estimated prevalence varies between regions and countries but ranges from $10 \%$ to $80 \% .^{1112}$ One of the common indications for herbal medicine use during pregnancy is prolonged labour or merely the desire to induce or augment labour for different reasons. ${ }^{13} 14$ This practice is well documented and transcends cultural and generational boundaries. ${ }^{14}$

From a medical perspective, induction of labour (IOL) changes the physiological processes associated with childbirth in ways that may increase the risk of adverse pregnancy outcomes such as neonatal mortality, fetal distress, premature birth, haemorrhage, 
uterine rupture and caesarean section. ${ }^{15-17}$ Because of this, WHO recommends that labour should only be induced in health facilities with the capacity for continual monitoring and emergency obstetric care. ${ }^{18}$ The emphasis on facility-based IOL and close monitoring of pregnant women demonstrates the risks associated with the procedure. Nonetheless, with herbal medicine-induced labour, monitoring of women is often out of the question due to self-prescription. ${ }^{2}{ }^{19}$ So, the use of herbal medicines for IOL is likely to be riskier and it is plausibly an important factor influencing adverse pregnancy outcomes in settings where its use is common.

In vitro studies have confirmed that some of the herbal medicines used during pregnancy have oxytocic properties. ${ }^{1320}$ For instance, a study in Nigeria found that several plants that are used to facilitate childbirth in the country significantly induced muscle cell contractility. ${ }^{13}$ However, safety is the main concern as many of the herbal medicines are believed to be poisonous and may contribute to maternal and neonatal mortality as well as morbidity. ${ }^{21} 22$ To date, there is mixed evidence from population-based studies regarding the efficacy and safety of herbal medicines for $\mathrm{IOL}^{23-25}$ and yet available data have not been systematically evaluated and synthesised to provide the rigorous evidence necessary to inform decisions. Lack of high quality and consistent data on efficacy and safety of herbal medicines makes recommendations and regulations challenging. ${ }^{5}$ Consequently, we conducted a systematic review to explore the effectiveness and safety of herbal medicines for IOL. This review is important to inform the development of guidelines relating to the use of herbal medicines among pregnant women.

\section{METHODS \\ Design}

This is a systematic review and meta-analysis of published literature on effectiveness and safety of herbal medicines for IOL. The reporting of the abstract (online supplementary file S1) and results (online supplementary file S2) are guided by the Preferred Reporting Items for Systematic Reviews and Meta-Analyses . ${ }^{26}$

\section{Data sources and searches}

We searched in MEDLINE, AMED and CINAHL from 13 February to 22 April 2017 and repeated this on 22 June 2018 using key terms such as herbal medicine, labour and pregnancy outcomes, which were modified in accordance with each database (online supplementary file S3). More papers were identified through scanning the reference list of studies found through the initial search as well as direct searches in the following journals: African Journals Online, Journal for Herbal Medicine, BMC Complementary and Alternative Medicine, Journal of Alternative and Complementary Medicine and Journal of Integrative Medicine.

\section{Inclusion/exclusion criteria}

The inclusion criteria were based on participant, intervention, control, outcomes and studies. We considered studies with pregnant or postpartum women as participants. The treatment or exposure was herbal medicines for induction or shortening of labour. For studies that did not explicitly indicate the reasons for use, the name of the medicine was used to determine if IOL was the possible motive. There was no restriction on dosage, but the route of administration was oral. The plants could be either processed or crude and used alone or alongside conventional medicines. An appropriate comparison group comprised either pregnant women who did not use the herbal medicine under consideration or used biomedical drugs exclusively. The maternal outcomes were haemorrhage, sepsis, caesarean section, uterine rupture, assisted vaginal delivery and maternal death; while the neonatal outcomes were stillbirth, premature birth, neonatal mortality, meconium-stained liquor (MSL)/fetal distress, birth defects and referral to neonatal intensive care unit (also known as nursery).

Due to ethical, safety and methodological issues, pregnant women are often excluded from randomised controlled/clinical trials (RCTs) and herbal medicines may not be evaluated through RCTs. ${ }^{27-29}$ Thus, observational studies are a common source of literature for efficacy and safety of herbal medicines in pregnancy. Accordingly, we considered both experimental and non-experimental study designs. In particular, the following study designs were eligible for inclusion: RCTs, quasi-experimental, cohort, case-control and cross-sectional. We only considered studies published in English or in other languages, but with a detailed English abstract. No restrictions were applied on the date of publication and study setting.

\section{Data extraction}

A data extraction form (online supplementary file S4) was developed specifically for this review based on templates developed by the Joanna Briggs Institute and the Cochrane Pregnancy and Childbirth Group. ${ }^{30} 31$ The form included specific details about the study design, participants, setting, intervention/exposure, control and outcomes. Owing to the focus of our study (ie, efficacy and safety), 'per protocol' treatment effects were preferred in RCTs. ${ }^{32}$ As none of the observational studies reported adjusted effect estimates, crude data were extracted and used in this review. Two reviewers- $\mathrm{CZ}$ and $\mathrm{CM}$ - separately extracted the data and any differences were resolved by discussion.

\section{Quality/risk of bias assessment}

Two different tools were used to assess the risk of bias in experimental and non-experimental studies that met the inclusion criteria. CZ and CM independently performed the risk of bias assessment and any disagreements were resolved by discussion. For experimental studies, Cochrane Risk of Bias tool for the RCTs ${ }^{33}$ was used and the following domains were assessed: random sequence generation, allocation concealment, blinding of participants, blinding of outcome assessment, incomplete 
outcome data, selective reporting and other biases (online supplementary file S5). Only abstracts were available in English for two studies ${ }^{25} 34$ and hence their risk of bias is largely unclear. The overall risk of bias for the other RCTs is low.

The risk of bias for non-experimental studies was assessed using a standardised critical appraisal tool developed by 'John Hopkins Nursing School'. 35 This tool divides the strength of research evidence into five levels based on the study design. The RCTs occupy the top level (level I) followed by quasi-experimental studies (level II) and other non-experimental studies (level III). The last two levels are for opinion-related papers either based on research evidence (level IV) or individual expertise (level V). The quality of evidence is further graded as high (A), good (B) and low quality or major flaws $(\mathrm{C})$ depending on the risk of bias and scientific basis for the conclusions. Based on this tool, a list of 10 questions (or domains) was developed to guide the assessment (online supplementary file S6). Since the review used crude data, the need to control extraneous variables and whether this was done (if required) were key factors in determining the study grade. For instance, grade $\mathrm{C}$ was given to studies in which the treatment and control groups were not comparable and confounders were not adjusted for. Two studies ${ }^{23}{ }^{36}$ received a grade of $\mathrm{C}$ and were eventually excluded from the review.

\section{Data analysis}

Meta-analyses were performed to compare the onset of labour (effectiveness) and the incidence of adverse pregnancy outcomes (safety) between the users and non-users of herbal medicines for IOL. As variations were expected between studies due to the differences in setting, design and types of herbal medicines, a random-effects model was used to synthesise effects sizes of the studies. ${ }^{37}$ Heterogeneity was explored through the $\mathrm{I}^{2}$ statistic and meta-analysis was conducted regardless of the outcome as random-effects model accommodates statistical heterogeneity. ${ }^{38}$ Subject to availability of the sufficient number of studies, subgroup analyses were conducted based on the type of treatment/exposure or study design to explain observed heterogeneity. Potential publication bias was assessed using Egger's test since all analyses had less than 10 studies to use a funnel plot method. ${ }^{39} 40$ Summary effects were measured using risk ratios (RRs) and all analyses were performed using Stata/SE V.13.1 software.

\section{Patient and public involvement}

As this was a review of existing literature, we did not involve any patient and the public in the design and conduct of the study. However, the development of the review question was informed by the experiences of pregnant women as observed in the literature.

\section{RESULTS}

\section{Study selection process}

Searches in the three databases returned a total of 1421 papers $(\mathrm{CINAHL}=420, \mathrm{AMED}=279$ and $\mathrm{MEDLINE}=723$ ).
After removal of duplicates $(\mathrm{n}=539)$, the titles and/ or abstracts of 882 publications were screened and 802 studies were dropped at this stage for various reasons (see figure 1). Full-text articles were retrieved for 80 studies for further eligibility assessment and 71 of them failed to meet the inclusion criteria. Additional potential relevant papers $(n=3)$ were identified through direct searches in journals and reference lists. Twelve papers were appraised in the final stage and two were excluded due to poor methodological quality (see online supplementary file S6). Thus, 10 studies were included in this review.

\section{An overview of the included studies}

Online supplementary file S7 presents the characteristics of the studies, such as location, exposure, outcomes and ratings. In brief, of the 10 studies in the review, three were conducted in Iran, two in the USA and one each in South Africa, Israel, Thailand, Australia and Italy. In relation to the World Bank's classification of countries by income, half of the studies were conducted in high-income countries and the other half in upper-middle-income countries (UMICs). No study from low-income countries (LICs) or lower-middle-income countries (LMICs) was included.

Three types of exposures were reported by the studies. An Australian study was concerned with exposure to raspberry leaf. ${ }^{41}$ This is one of the common herbal remedies used during pregnancy that is believed to prepare the uterus for childbirth and thereby effectively reduce the length of labour. ${ }^{14}$ In this study, exposure was self-reported by the participants as they were given raspberry pills by the nurses to take at home. Eight studies examined exposure to castor oil. ${ }^{25} 3442-47$ The oil is derived from the castor plant's bean and is widely thought to have oxytocic properties. ${ }^{44}{ }^{45}$ In all the studies, pregnant women consumed $60 \mathrm{~mL}$ of castor oil, but in one study ${ }^{43}$ the treatment was repeated in women who did not deliver within 1 week after the first dose. One study ${ }^{48}$ assessed general exposure to herbal medicines, but there are indications in the report that they were for IOL.

Five of the included studies are RCTs and the remaining five are non-experimental, including cohort (3), case-control (1) and quasi-experimental (1) designs. The following pregnancy outcomes were reported by the included studies: onset of labour within 24 hours, caesarean section, haemorrhage, neonatal referral to nursery care, MSL, assisted vaginal delivery, stillbirth, neonatal death, maternal death and uterus rupture.

\section{Outcome 1: onset of labour within 24 hours}

Eight studies explored the onset of labour within 24 hours after the use of herbal medicine for IOL. Castor oil was the exposure or intervention in all the studies. As shown in figure 2, herbal medicine users were significantly more likely to give birth within 24 hours than non-users (RR 3.46; 95\% CI 1.58 to 7.55 ). In the subgroup analysis by study design, similar results were observed among experimental studies, but there was no significant difference in onset of labour between users and non-users 


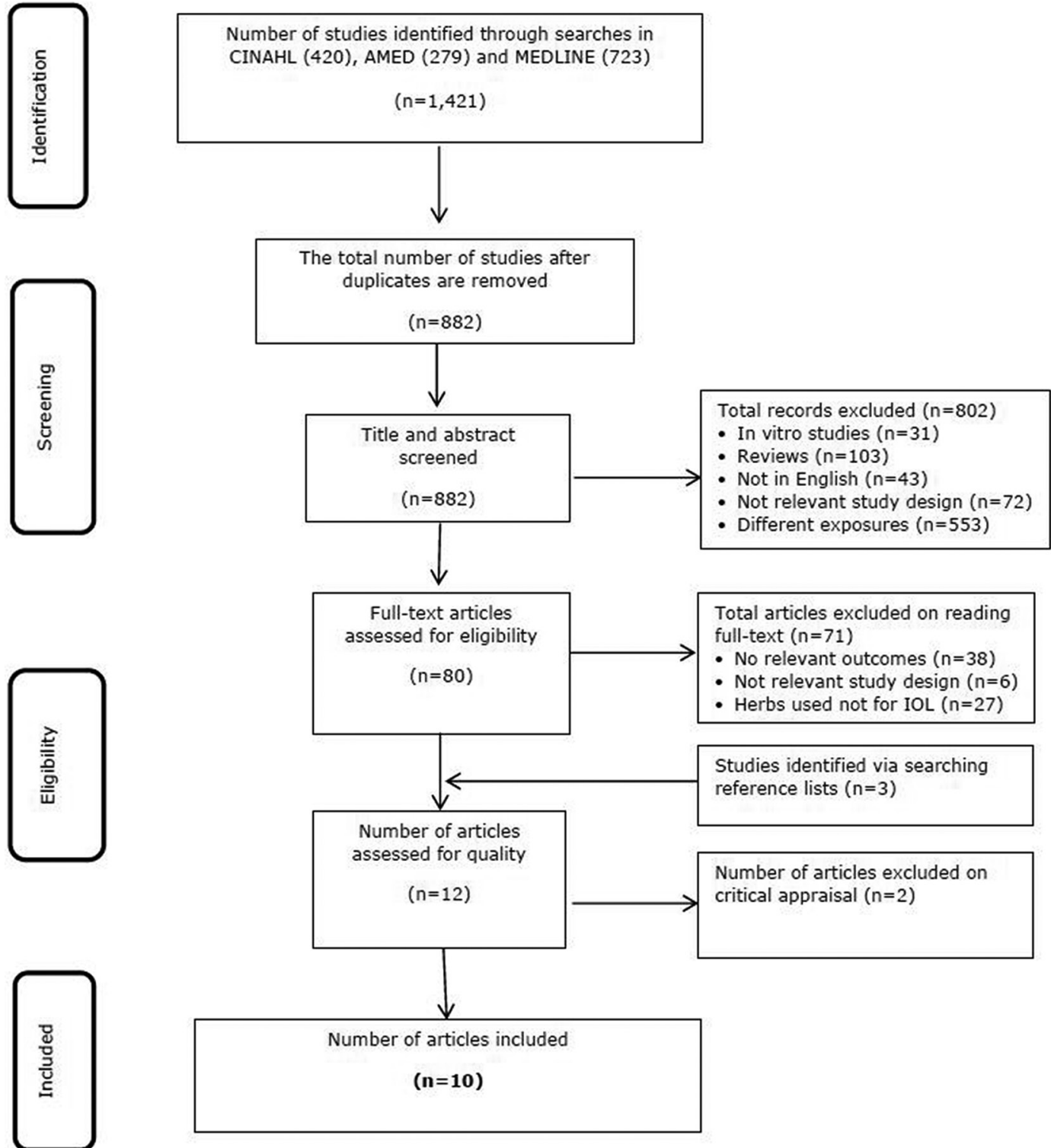

Figure 1 A PRISMA flow diagram summarising the study selection process. IOL, induction of labour; PRISMA, Preferred Reporting Items for Systematic Reviews and Meta-Analyses.

among the non-experimental studies (online supplementary file S8). Publication bias was not an issue (bias 3.23; $95 \%$ CI 0.48 to 5.97$)$, but heterogeneity was significant $\left(\mathrm{I}^{2}=90.2 \%, \mathrm{p} \leq 0.001\right)$ and this was likely due to variations in study design and or setting.

\section{Outcome 2: incidence of caesarean section}

The association between herbal medicine use and occurrence of caesarean section was examined by six studies. A meta-analysis (figure 3) found no significant difference in the rate of caesarean section between the users and non-users of herbal medicines (RR 1.19; $95 \%$ CI 0.76 to 1.86). Similar results were observed in subgroup analysis by type of treatment (online supplementary file S9) and study design (online supplementary file S10), except that Mabina $e t a t^{8}$ (eg, any exposure), found a significant difference in the incidence of caesarean section between the study groups. Both heterogeneity $\left(\mathrm{I}^{2}=45.6 \% ; \mathrm{p}=0.102\right)$ and publication bias were not significant (Bias=-0.39; $95 \%$ CI -4.47 to 3.70 ).

\section{Outcome 3: incidence of assisted vaginal delivery}

In this review, assisted vaginal delivery was defined as the use of medical interventions such as forceps and or episiotomy to aid delivery. This outcome was reported by five studies and a meta-analysis (figure 4) found no significant difference between the users and non-users of herbal medicines (RR $0.73 ; 95 \%$ CI 0.47 to 1.14 ). Heterogeneity was significant $\left(I^{2}=74.4 \%\right.$; $\left.p=0.004\right)$, but publication bias was not (Bias $=-1.87 ; 95 \%$ CI -6.12 to 2.38). Subgroup analyses by type of treatment (online supplementary file S11) and study design (online supplementary file S12) did not substantially change the results. 


\begin{tabular}{|c|c|c|c|c|c|}
\hline \multicolumn{3}{|l|}{ Study } & $\begin{array}{l}\text { Events, } \\
\text { Herbs }\end{array}$ & $\begin{array}{l}\text { Events, } \\
\text { No-herbs }\end{array}$ & $\begin{array}{l}\% \\
\text { Weight }\end{array}$ \\
\hline Davis (1984) & $\rightarrow$ & $1.28(1.04,1.57)$ & $80 / 107$ & $52 / 89$ & 16.12 \\
\hline Garry (2000) & & $13.85(3.50,54.85)$ & $30 / 52$ & $2 / 48$ & 10.83 \\
\hline Azhari (2006) & & $12.46(1.77,87.73)$ & $13 / 24$ & $1 / 23$ & 8.08 \\
\hline Pirdadeh (2007) & & $>12.46(1.77,87.73)$ & $13 / 24$ & $1 / 23$ & 8.08 \\
\hline Saberi (2008) & & $5.83(3.38,10.07)$ & $70 / 100$ & $12 / 100$ & 15.10 \\
\hline Boel (2009) & & $0.93(0.48,1.81)$ & $8 / 43$ & $68 / 341$ & 14.60 \\
\hline Neri (2018) & & $6.33(2.03,19.72)$ & $19 / 40$ & $3 / 40$ & 12.12 \\
\hline Gilad (2018) & $\rightarrow$ & $1.21(0.69,2.10)$ & $16 / 38$ & $15 / 43$ & 15.07 \\
\hline Overall $(\mathrm{I}-$ squared $=90.2 \%, p=0.000)$ & $\mathrm{x}=\mathrm{n}$ & $3.46(1.58,7.55)$ & $249 / 428$ & $154 / 707$ & 100.00 \\
\hline NOTE: Weights are from random effects analysis & & & & & \\
\hline
\end{tabular}

Figure 2 The use of herbal medicines for induction of labour and onset of labour. RR, risk ratio.

\section{Outcome 4: incidence of haemorrhage}

The occurrence of haemorrhage among users and non-users of herbal medicines for IOL was assessed by four studies and a meta-analysis (figure 5) shows no significant difference between the two groups (RR 0.84; $95 \%$ CI 0.44 to 1.60 ). These results were consistent with those in subgroup analyses by type of treatment (online supplementary file S13) as well as study design (online supplementary file S14). Heterogeneity was almost non-existent $\left(\mathrm{I}^{2}=0.0 \% ; \mathrm{p}=0.802\right)$ and publication bias was not significant (Bias $0.49 ; 95 \%$ CI -2.73 to 3.70 ).

\section{Outcome 5: incidence of MSL}

The occurrence of MSL, a strong indicator of fetal distress, ${ }^{49}$ was reported by five studies. Overall, there is no significant difference in the rate of MSL between users and non-users of herbal medicines (RR 1.20; 95\% CI 0.65 to 2.23) (figure 6). Comparable results were observed in subgroup analysis by type of treatment (online supplementary file S15). However, in subgroup analysis by study design, the experimental studies tended to favour treatment while the non-experimental inclined towards control, but both results were not statistically significant (online supplementary file S16). Publication bias was not significant (Bias=-2.38; 95\% CI -6.76 to 2.00 ), but heterogeneity was high $\left(I^{2}=77.9 \% ; p=0.001\right)$ probably due to variations across studies.

\section{Outcome 6: neonates' admission to nursery}

Whether a newborn child is referred to neonatal intensive care unit (also known as nursery) or not is often used as an indicator for well-being. ${ }^{41}$ This outcome was reported by three studies and none of them individually found a significant difference in admission to nursery between users and non-users of herbal medicines for IOL. A meta-analysis (figure 7) found no significant difference between the two groups (RR 1.08; 95\% CI 0.49 to 2.38). Both publication bias (bias $=-1.51 ; 95 \%$ CI -7.66 to 4.64 ) and heterogeneity $\left(I^{2}=0.0 \% ; p=0.482\right)$ were not significant. Subgroup analysis was not performed due to the inadequate number of studies.

\section{Other outcomes}

The following outcomes were either reported by a single study or there was insufficient data and hence meta-analyses were not performed: maternal death, stillbirth

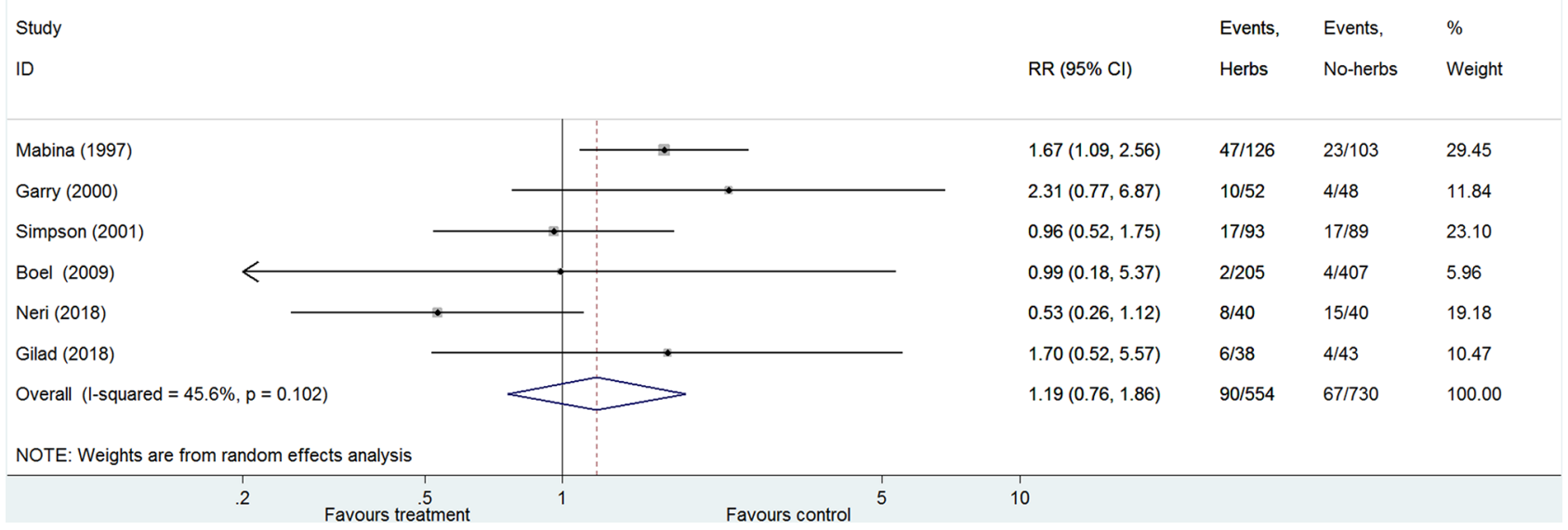

Figure 3 The use of herbal medicines for induction of labour and the incidence of caesarean section. RR, risk ratio. 


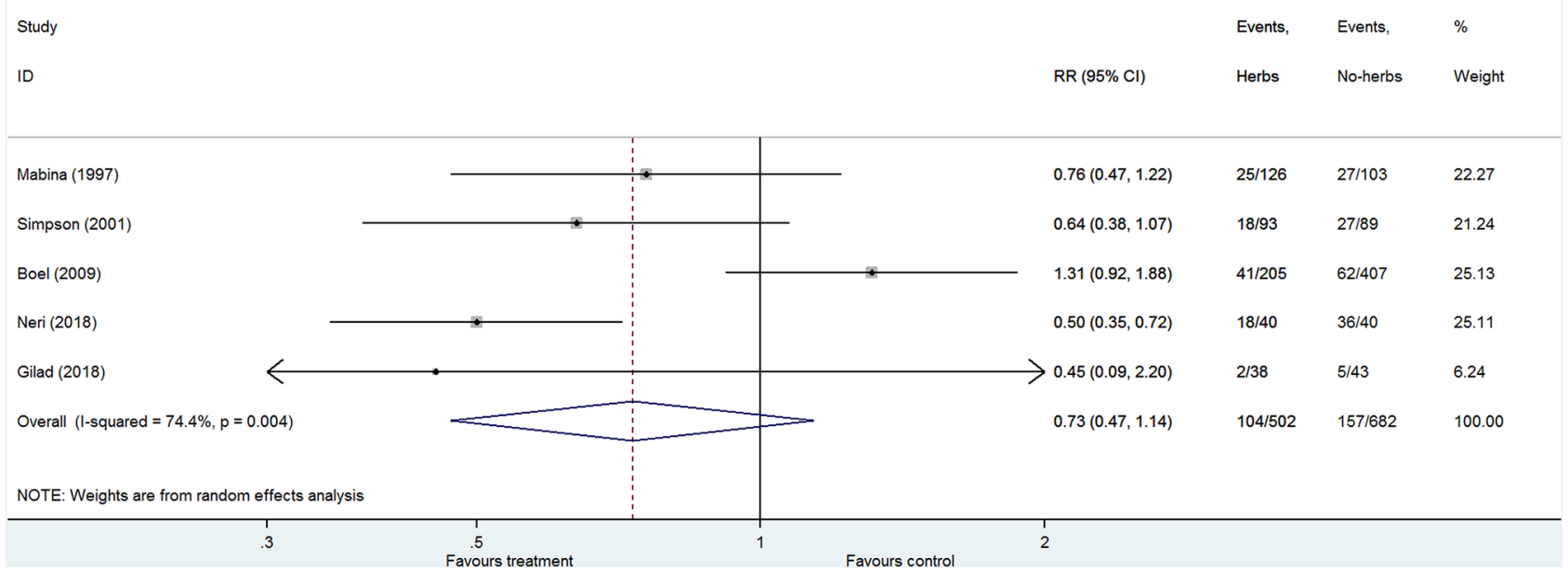

Figure 4 The use of herbal medicines for induction of labour and the incidence of assisted vaginal delivery. RR, risk ratio.

and uterine rupture. A single study assessed maternal death and stillbirth outcomes among users $(\mathrm{n}=205)$ and non-users $(n=407)$ of castor oil to induce labour. ${ }^{43}$ No maternal death occurred in either group, but one case of stillbirth $(0.3 \%)$ was reported in the control group. Uterine rupture was reported by two studies in relation to castor oil and only one case was reported among exposed women in one of the studies. ${ }^{43}$ Overall, no study found a significant difference in any of the three outcomes between users and non-users of herbal medicines for IOL.

\section{DISCUSSION}

We have found that herbal medicines for IOL are effective and there is no concrete evidence of association with adverse outcomes. On efficacy, we have found that women who used the herbal medicines were significantly more likely to give birth within 24 hours than their counterparts who did not use. This corroborates many in vitro studies around the world that have shown that some herbal medicines effectively induce uterine contractions. ${ }^{1320}{ }^{50}$ For instance, studies in Malawi and Nigeria have established that some medicinal plants commonly prescribed by traditional healers to induce childbirth have oxytocic properties. ${ }^{1320}$ Previous reviews, however, found insufficient evidence for the effectiveness of herbal medicines for IOL. ${ }^{51}{ }^{52}$ This contradiction could be as a result of the differences in inclusion criteria. Most of the related reviews excluded non-experimental studies, ${ }^{51} 52$ which are a common source of efficacy data due to safety issues surrounding RCTs for herbal medicines or pregnant women. ${ }^{27} 2853$ Whereas this allowed us to assess a wider evidence base than the previous reviews, we are also mindful of the biases inherent in observational studies. Therefore, a definite conclusion about the efficacy of

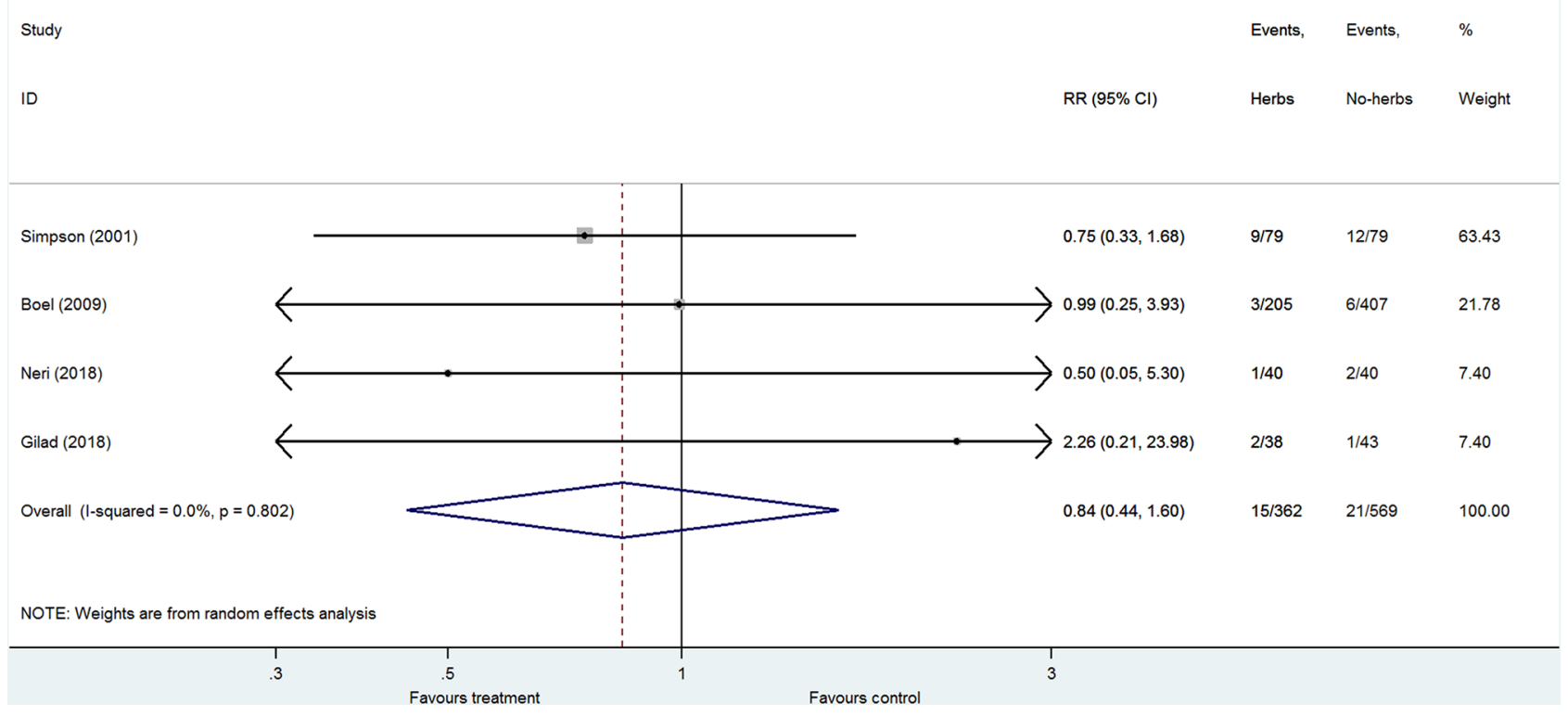

Figure 5 The use of herbal medicines for induction of labour and the incidence of haemorrhage. RR, risk ratio. 


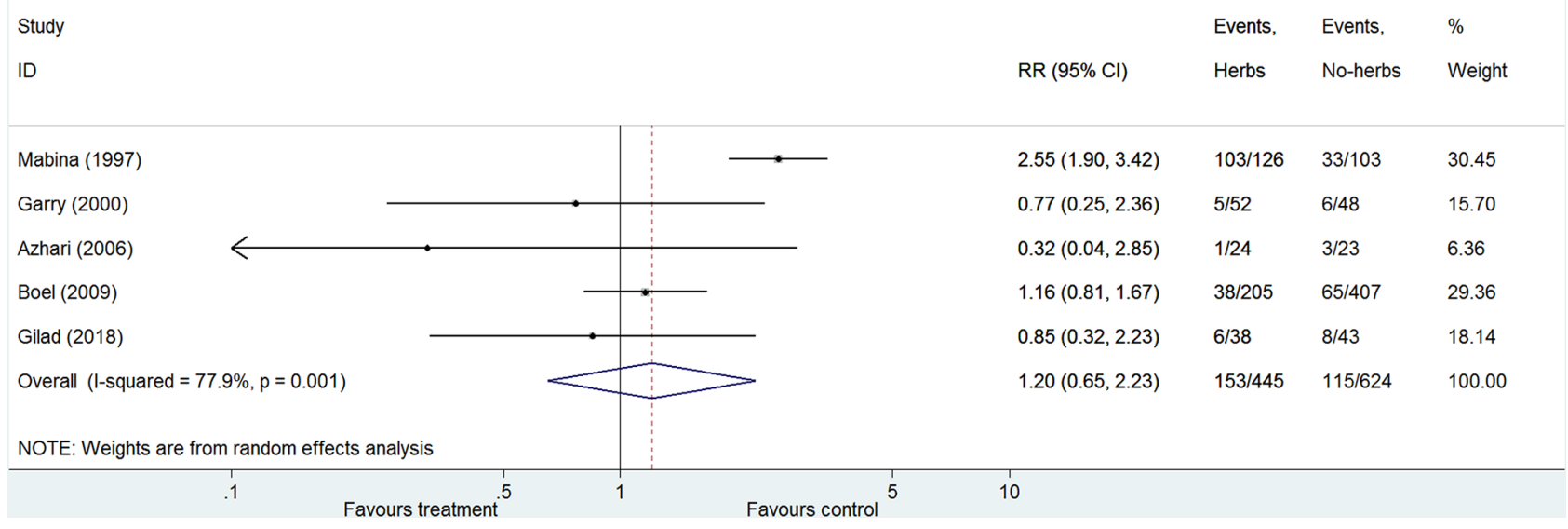

Figure 6 The use of herbal medicines for induction of labour and the incidence of meconium-stained liquor. RR, risk ratio.

herbal remedies for IOL cannot be put forward based on the present review. ${ }^{54-56}$

On safety, we did not find any statistically significant difference in the rate of haemorrhage, caesarean section, assisted vaginal delivery, referral to neonatal intensive care unit, MSL, maternal death, stillborn and uterine rupture between participants in treated and control groups. The implication is that herbal medicines for IOL may not be harmful to women or neonates. This observation is consistent with the results that have been reported by other reviews on a related topic. ${ }^{52}$ Notwithstanding, caution must be exercised in the interpretation of this data because in some outcomes (eg, caesarean section) the difference in the number of cases between treated and control groups was very high. This was also noted by Boltman-Binkowski $^{51}$ in her review. Despite lack of statistical significance, she argues that a higher number of adverse outcomes among women who ingested castor oil implies that the link between the two cannot be entirely dismissed. The finding may also be inconclusive owing to lack of data on key outcomes, such as maternal death, sepsis and neonatal death.

The results of this review should be considered in the context of the following limitations and biases. First, although the baseline characteristics of the observational studies were similar across study groups, not all potential confounders were measured. Likewise, of the five RCTs in this review, three were unclear on selection, performance and detection biases while two had unclear attrition, reporting and other biases. Thus, the risk of bias may have been introduced as a result of these poor methodologies. In addition, some analyses lacked adequate statistical power because of small sample sizes or the insufficient number of studies. These issues strongly suggest that the outcomes of this review be treated with considerable caution.

Second, in almost all the studies, herbal remedies were provided at the health facility and pregnant women were somewhat monitored by clinical staff. In this way, many potential adverse events may have been averted or lessened. Nevertheless, this does not entirely represent the reality of the context in which herbal medicines are taken, and thus, the results of these studies may be misleading. In sub-Saharan Africa, for instance, herbal medicines are often taken outside the health facility without the knowledge and support of healthcare providers. ${ }^{12} 4857$ In such situations, the risk of adverse events could be higher than reported by these studies.

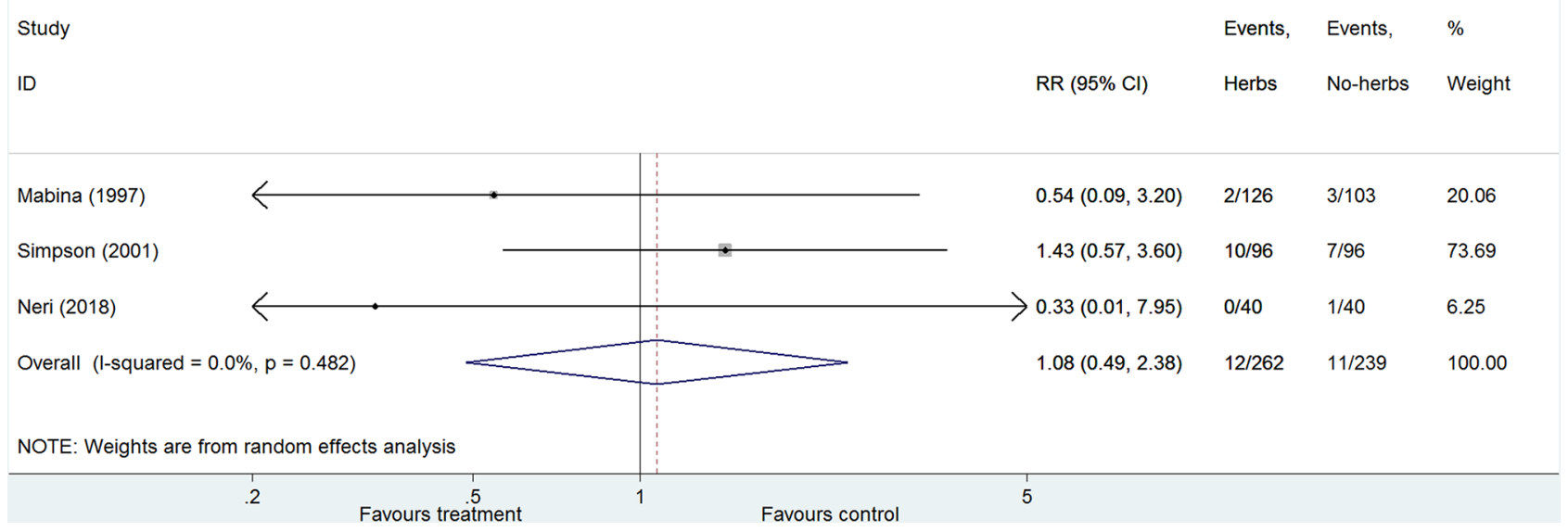

Figure 7 The use of herbal medicines for induction of labour and neonatal admission to nursery. RR, risk ratio. 
Lastly, all studies in this review are from higher and UMICs. No study from a low or LMIC was included. This probably suggests lack of studies on this subject in limited-resource settings. Hence, the findings of this review cannot be extrapolated beyond higher and UMICs. Since the issue of safety of herbal medicines in pregnancy relates to maternal as well as neonatal morbidity and mortality, ${ }^{22} 4858-60$ which are principally the problems of LIC, ${ }^{61}{ }^{62}$ high-quality studies that include a range of maternal morbidity and mortality outcomes in LIC are urgently needed. ${ }^{22} 63$

\section{CONCLUSIONS AND IMPLICATIONS}

The evidence from this review suggests that herbal medicines for IOL are effective, but their safety among women and neonates require further exploration. Therefore, we would not recommend the use of these medicines until all the safety concerns are adequately addressed. In the meantime, larger safety and efficacy studies with sufficient statistical power and of high methodological quality should be conducted to improve the evidence base.

\section{Twitter@czamawe}

Acknowledgements We are grateful to Tim Colbourn for his technical advice on meta-analysis.

Contributors $\mathrm{CZ}$, CK, $\mathrm{HMJ}$ and $\mathrm{EF}$ conceived the review. $\mathrm{CZ}$ and $\mathrm{CM}$ conducted the literature search, appraised the papers and extracted the data. $\mathrm{CZ}$ performed the analysis and drafted the manuscript. CK and EF commented on drafts and provided technical input at all stages. All authors have read and approved the final manuscript.

Funding Collins Zamawe is a Commonwealth Scholar supported by the UK Government (CSC-2016-795).

Competing interests None declared.

Patient consent Not required.

Provenance and peer review Not commissioned; externally peer reviewed.

Data sharing statement All data used in this review can be accessed from the corresponding author.

Open access This is an open access article distributed in accordance with the Creative Commons Attribution Non Commercial (CC BY-NC 4.0) license, which permits others to distribute, remix, adapt, build upon this work non-commercially, and license their derivative works on different terms, provided the original work is properly cited, appropriate credit is given, any changes made indicated, and the use is non-commercial. See: http://creativecommons.org/licenses/by-nc/4.0/.

\section{REFERENCES}

1. Kyomuhendo GB. Low use of rural maternity services in Uganda: impact of women's status, traditional beliefs and limited resources. Reprod Health Matters 2003;11:16-26.

2. Maimbolwa MC, Yamba B, Diwan V, et al. Cultural childbirth practices and beliefs in Zambia. J Adv Nurs 2003;43:263-74.

3. Holst L, Wright D, Nordeng $\mathrm{H}$, et al. Use of herbal preparations during pregnancy: focus group discussion among expectant mothers attending a hospital antenatal clinic in Norwich, UK. Complement Ther Clin Pract 2009;15:225-9.

4. Westfall RE. Herbal healing in pregnancy: women's experiences. $J$ Herb Pharmacother 2003;3:17-39.

5. World Health Organisation. WHO Traditional Medicine Strategy. Geneva 2014.

6. World Health Organisation. Guidelines on Developing Consumer Information on Proper Use of Traditional, Complementary and Alternative Medicine. Geneva: World Health Organisation, 2004.
7. Al-Ramahi R, Jaradat N, Adawi D. Use of herbal medicines during pregnancy in a group of Palestinian women. J Ethnopharmacol 2013;150:79-84.

8. Chuang $\mathrm{CH}$, Chang PJ, Hsieh WS, et al. Chinese herbal medicine use in Taiwan during pregnancy and the postpartum period: a population-based cohort study. Int J Nurs Stud 2009;46:787-95.

9. Frawley J, Adams J, Steel A, et al. Women's Use and SelfPrescription of Herbal Medicine during Pregnancy: An Examination of 1,835 Pregnant Women. Womens Health Issues 2015;25:396-402.

10. Laelago T, Yohannes T, Lemango F. Prevalence of herbal medicine use and associated factors among pregnant women attending antenatal care at public health facilities in Hossana Town, Southern Ethiopia: facility based cross sectional study. Arch Public Health 2016;74:7.

11. Ali-Shtayeh MS, Jamous RM, Jamous RM. Plants used during pregnancy, childbirth, postpartum and infant healthcare in Palestine. Complement Ther Clin Pract 2015;21:84-93.

12. Mureyi DD, Monera TG, Maponga CC. Prevalence and patterns of prenatal use of traditional medicine among women at selected harare clinics: a cross-sectional study. BMC Complement Altern Med 2012;12:164-70.

13. Attah AF, O'Brien M, Koehbach J, et al. Uterine contractility of plants used to facilitate childbirth in Nigerian ethnomedicine. J Ethnopharmacol 2012;143:377-82.

14. Hall HG, McKenna LG, Griffiths DL. Complementary and alternative medicine for induction of labour. Women Birth 2012;25:142-8.

15. Smid M, Ahmed Y, Ivester T. Special considerations--Induction of labor in low-resource settings. Semin Perinatol 2015;39:430-6.

16. Lothian JA. Saying "No" to Induction. J Perinat Educ 2006;15:43-5.

17. Guerra GV, Cecatti JG, Souza JP, et al. Factors and outcomes associated with the induction of labour in Latin America. BJOG 2009; $116: 1762-72$

18. World Health Organization. WHO recommendations for Induction of Labour. Geneva 2011.

19. Beste J, Asanti D, Nsabimana D, et al. Use of Traditional Botanical Medicines During Pregnancy in Rural Rwanda. J Glob Health Perspect 2015;2015.

20. Bullough $\mathrm{CH}$, Leary WP. Herbal medicines used by traditional birth attendants in Malawii. Trop Geogr Med 1982;34:81-5.

21. Veale DJ, Furman KI, Oliver DW. South African traditional herbal medicines used during pregnancy and childbirth. J Ethnopharmacol 1992;36:185-91.

22. Bullough $\mathrm{CH}$. Analysis of maternal deaths in the Central Region of Malawi. East Afr Med J 1981;58:25-36.

23. Lamadah S, Mohamed H, El-Khedr S. Castor Oil Safety and Effectiveness on Labour Induction and Neonatal Outcome. Journal of Biology, Agriculture and Healthcare 2014;4.

24. Qiu H, Zhu H, Ouyang W, et al. Clinical effects and mechanism of chanlibao in accelerating second stage of labor. J Tongji Med Univ 1999;19:141-4.

25. Saberi F, Abedzadeh M, Sadat Z, et al. Effect of castor oil on induction of labor. Feyz Journal of Kashan University of Medical Sciences 2008;11:19-23.

26. Liberati A, Altman DG, Tetzlaff J, et al. The PRISMA statement for reporting systematic reviews and meta-analyses of studies that evaluate healthcare interventions: explanation and elaboration. BMJ 2009;339:b2700.

27. Frew PM, Saint-Victor DS, Isaacs MB, et al. Recruitment and retention of pregnant women into clinical research trials: an overview of challenges, facilitators, and best practices. Clin Infect Dis 2014;59:S400-7.

28. Merkatz RB, Temple R, Sobel S, et al. Women in Clinical Trials of New Drugs -- A Change in Food and Drug Administration Policy. N Engl J Med Overseas Ed 1993;329:292-6.

29. Parveen A, Parveen B, Parveen R, et al. Challenges and guidelines for clinical trial of herbal drugs. J Pharm Bioallied Sci 2015;7:329-33.

30. Cochrane Pregnancy and Childbirth Group, 2017. Author resources for NEW REVIEWS: The Cochrane Collaboration http://pregnancy. cochrane.org/author-resources-new-reviews (accessed 12 May 2017).

31. The Joanna Briggs Institute. Joanna Briggs Institute Reviewers' Manual. 2014 edn. South Australia: The Joanna Briggs Institute, 2014.

32. Sedgwick P. Intention to treat analysis versus per protocol analysis of trial data. BMJ 2015;350:h681.

33. Higgins JP, Altman DG, Gøtzsche PC, et al. The Cochrane Collaboration's tool for assessing risk of bias in randomised trials. BMJ 2011;343:d5928.

34. Pirdadeh Beiranvand S, Azhari S, Lotfalizadeh M. The effect of castor oil on initiating labor in 40-42 weeks pregnancy. J Babol Univ Med Sci 2007;9:33-8. 
35. Dang D, Dearholt S. Johns Hopkins Nursing evidence-based practice: model and guidelines. 3rd edn. Indianapolis: Sigma Theta Tau International, 2017.

36. Parsons M, Simpson M, Ponton T. Raspberry leaf and its effect on labour: safety and efficacy. Aust Coll Midwives Inc J 1999;12:20-5.

37. Borenstein M, Hedges LV, Higgins JP, et al. A basic introduction to fixed-effect and random-effects models for meta-analysis. Res Synth Methods 2010;1:97-111.

38. Ioannidis JP, Patsopoulos NA, Rothstein HR. Reasons or excuses for avoiding meta-analysis in forest plots. BMJ 2008;336:1413-5.

39. Deeks JJ, Higgins JPT, Altman DG. Analysing data and undertaking meta-analyses. In: Higgins J, Green S, eds. Cochrane Handbook for Systematic Reviews of Interventions, 2011.

40. Egger M, Davey Smith G, Schneider M, et al. Bias in meta-analysis detected by a simple, graphical test. BMJ 1997;315:629-34.

41. Simpson M, Parsons M, Greenwood J, et al. Raspberry leaf in pregnancy: its safety and efficacy in labor. $J$ Midwifery Womens Health 2001;46:51-9.

42. Azhari S, Pirdadeh S, Lotfalizadeh M, et al. Evaluation of the effect of castor oil on initiating labor in term pregnancy. Saudi Med $J$ 2006;27:1011-4.

43. Boel ME, Lee SJ, Rijken MJ, et al. Castor oil for induction of labour: not harmful, not helpful. Aust N Z J Obstet Gynaecol 2009;49:499-503.

44. Davis $\mathrm{L}$. The use of castor oil to stimulate labor in patients with premature rupture of membranes. J Nurse Midwifery 1984;29:366-70.

45. Garry D, Figueroa R, Guillaume J, et al. Use of castor oil in pregnancies at term. Altern Ther Health Med 2000;6:77-9.

46. Gilad R, Hochner H, Savitsky B, et al. Castor oil for induction of labor in post-date pregnancies: A randomized controlled trial. Women Birth 2018;31:e26-e31.

47. Neri I, Dante G, Pignatti L, et al. Castor oil for induction of labour: a retrospective study. J Matern Fetal Neonatal Med 2018;31:2105-8.

48. Mabina MH, Pitsoe SB, Moodley J. The effect of traditional herbal medicines on pregnancy outcome. The King Edward VIII Hospital experience. S Afr Med J 1997;87:1008-10.

49. Fleischer A, Anyaegbunam A, Guidetti D, et al. A persistent clinical problem: profile of the term infant with significant respiratory complications. Obstet Gynecol 1992;79:185-90.
50. Nikolajsen $\mathrm{T}$, Nielsen $\mathrm{F}$, Rasch $\mathrm{V}$, et al. Uterine contraction induced by Tanzanian plants used to induce abortion. $J$ Ethnopharmacol 2011;137:921-5.

51. Boltman-Binkowski H. A systematic review: Are herbal and homeopathic remedies used during pregnancy safe? Curationis 2016;39:1514.

52. Kelly AJ, Kavanagh J, Thomas J. Cochrane Pregnancy and Childbirth Group. Castor oil, bath and/or enema for cervical priming and induction of labour. Cochrane Database Syst Rev 2013;27.

53. Firenzuoli F, Gori L. Herbal medicine today: clinical and research issues. Evid Based Complement Alternat Med 2007;4:37-40.

54. Pandis N. Bias in observational studies. Am J Orthod Dentofacial Orthop 2014;145:542-3.

55. Boyko EJ. Observational research--opportunities and limitations. J Diabetes Complications 2013;27:642-8.

56. Sedgwick P. Bias in observational study designs: case-control studies. BMJ 2015;350:h560.

57. Mothupi MC. Use of herbal medicine during pregnancy among women with access to public healthcare in Nairobi, Kenya: a crosssectional survey. BMC Complement Altern Med 2014;14:432-32.

58. Ab Rahman A, Ahmad Z, Naing L, et al. The use of herbal medicines during pregnancy and perinatal mortality in Tumpat District, Kelantan, Malaysia. Southeast Asian J Trop Med Public Health 2007;38:1150-7.

59. Chuang $\mathrm{CH}$, Doyle P, Wang JD, et al. Herbal medicines used during the first trimester and major congenital malformations: an analysis of data from a pregnancy cohort study. Drug Saf 2006;29:537-48.

60. Cuzzolin L, Francini-Pesenti F, Verlato G, et al. Use of herbal products among 392 Italian pregnant women: focus on pregnancy outcome. Pharmacoepidemiol Drug Saf 2010;19:1151-8.

61. Ronsmans C, Graham WJ. Lancet Maternal Survival Series steering g. Maternal mortality: who, when, where, and why. Lancet 2006;368:1189-200.

62. WHO, UNICEF, UNFPA. Trends in maternal mortality: 1990 to 2015: estimates by WHO, UNICEF, UNFPA, World Bank Group and the United Nations Population Division. Geveva: World Health Organization, 2015.

63. Mataya R. Report on the confidential enquiry into maternal deaths in Malawi (2008-2012): Lilongwe, 2015. 